\title{
EVALUATION OF AXIAL IMPREGNATION AS AN ALTERNATIVE TO CLASSICAL WOOD VACUUM PRESSURE IMPREGNATION METHOD
}

\author{
Jérémie Damay ${ }^{1,3,4}$, Emmanuel Fredon ${ }^{1,2}$, Philippe Gérardin ${ }^{1,3,4}$, Philippe Lemmens $^{4}$
}

\begin{abstract}
The evolution of laws on the use of biocide products has led to important changes in the field of wood preservation leading to an increasing interest for non "biocidal treatments" like thermal or chemical modifications. While thermal modifications become more and more common on industrial scale, development of chemical modifications progresses slowly. One reason for the challenges encountered is probably the difficulty to use actual vacuum pressure plant to impregnate wood with solutions of reactive chemicals aimed to react with or within the wood. In this context, the presented research focuses on a new alternative called axial impregnation, derived from Boucherie process, for impregnation of treatable non durable hardwood species. This process consists of low-pressure impregnation of green wood logs through its lower extremity with treatment solution transiting via natural pathways of vessels. In order to evaluate the feasibility of the method, logs of different hardwood species were impregnated with a copper based preservative solution and the distribution of copper within the wood was determined. Results indicated that treatable wood species like beech, hornbeam and birch can be easily and homogeneously treated using axial impregnation method, while ash known for its weak impregnability remained untreated.
\end{abstract}

Keywords: Impregnation, copper, preservation, treatability, wood.

\section{INTRODUCTION}

Wood is naturally degraded by numerous agents including micro-organisms, insects and UV. According to the species, natural durability of wood may be more or less important which determines the usage or not of a preservation method for a given application. However, the protection of non durable wood species remains a necessity to ensure their utilization in conditions where they are subjected to degradations caused by abiotic and biotic agents causing the ruin of the infested wood (Rayzal 2002). Thus, the choice of the wood species and the appropriate protection treatment, concerning both preservative product and its way of application, should be carefully chosen to extend the lifetime of a wooden structure.

Different techniques can be used to protect wood. The impregnation of biocides within the wood is still currently the most common method, although new processes such as heat treatment (Hakkou et al. 2006) or chemical modifications are experiencing a major boom (Rowell et al. 2009, Hill 2006). With regard to the impregnation of wood, there are many methods depending on the type of product to be applied, the required depth of penetration and final utilization of treated wood. The most superficial treatments are distinguished from the treatments allowing a deep impregnation. Superficial treatment can be achieved by brushing, spraying, dipping and the sap displacement, while autoclave treatments using vacuum and pressure are generally required for deeper impregnation. The type of treatment and

\footnotetext{
Laboratoire d'Etudes et de Recherche sur le Matériau Bois (LERMaB), EA 4370 - Université de Lorraine, Nancy, Francia

ENSTIB,Épinal, France. emmanuel.fredon@univ-lorraine.fr

${ }^{3}$ Faculté des Sciences et Technologies, BP 70239 - 54506, Vandœuvre-lès-Nancy, Francia. jeremie.damay@gmail.com

${ }^{4}$ Centre du Bois de Thiérache - 59132 Trélon,France.p.lemmens@free.fr

^ Corresponding author : philippe.gerardin@univ-lorraine.fr

Received : 17.12.2014 Accepted : 08.08. 2015
} 
the type of chemical used determine the possible applications of the treated wood (Thomasson et al. 2006). Vacuum pressure treatment plants require a huge investment, and have some disadvantages, especially for the implementation of treatments based on reactive solutions. Indeed, in an autoclave, the planks are spaced apart by the slats, and all the empty space around the planks must be filled with the impregnating solution, which involves reusing the solution by supplementing for economic purposes. Moreover, utilization of impregnation solutions containing highly reactive chemicals can lead to important problems in case of uncontrolled reactions, especially with polymerizable resins or monomers which can solidify in the reactor.

In this context, the Thiérache Wood Centre developed within the framework of several European programs, the axial impregnation technology. This technology, derived from the Boucherie process, should allow the homogeneous impregnation of the heartwood of treatable hardwood species on a freshly cut log just after felling. Contrary to the Boucherie process aimed to impregnate only the sapwood of softwood species by sap displacement, the axial impregnation process is aimed to impregnate the whole wood, heartwood and sapwood, of treatable species. Utilization of freshly cut green wood exempt of any defect is aimed to avoid inhomogeneous treatment resulting from preferential displacement of the impregnation solution through fissures in the log due to drying. It is particularly suitable for the treatment of European non durable hardwoods, like beech, allowing local development along with the valorization of this underexploited resource in France. Another advantage of the axial impregnation method, compared with vacuum/pressure methods conventionally used by industrial impregnation plants, is to use only the volume of impregnation solution required, which avoids the problems associated with the reuse of large volumes of solutions. Although many internal tests at the Thiérache Wood Centre have proved the effectiveness of the axial impregnation method, so that two pre-industrial processing prototypes have been developed, no rigorous study have been yet carried out showing that this method ensures uniform distribution of impregnated product. The aim of this paper is to validate the uniformity of copper distribution in wood using axial impregnation of a commercially available copper based preservation product Tanalith E3492.

\section{MATERIALS AND METHODS}

\section{Choice of wood species}

Trees used for axial impregnation test grew in Aubenton forest, in the North of France. One tree per species has been cut down especially for the axial impregnation test, at the end of April, just before the bud burst. Because the aim of the study was to assess the feasibility of the method on different hardwood species, only one tree per species was used. At the moment of the felling, the orientation of the logs (up / down direction or crown / root) was marked in order to correctly place the impregnation bell during processing.

Four hardwood species have been impregnated with the axial impregnation prototype shown in Figure 1: birch (Betula pubescens), hornbeam (Carpinus betulus), ash (Fraxinus excelsior) and beech (Fagus sylvatica). 


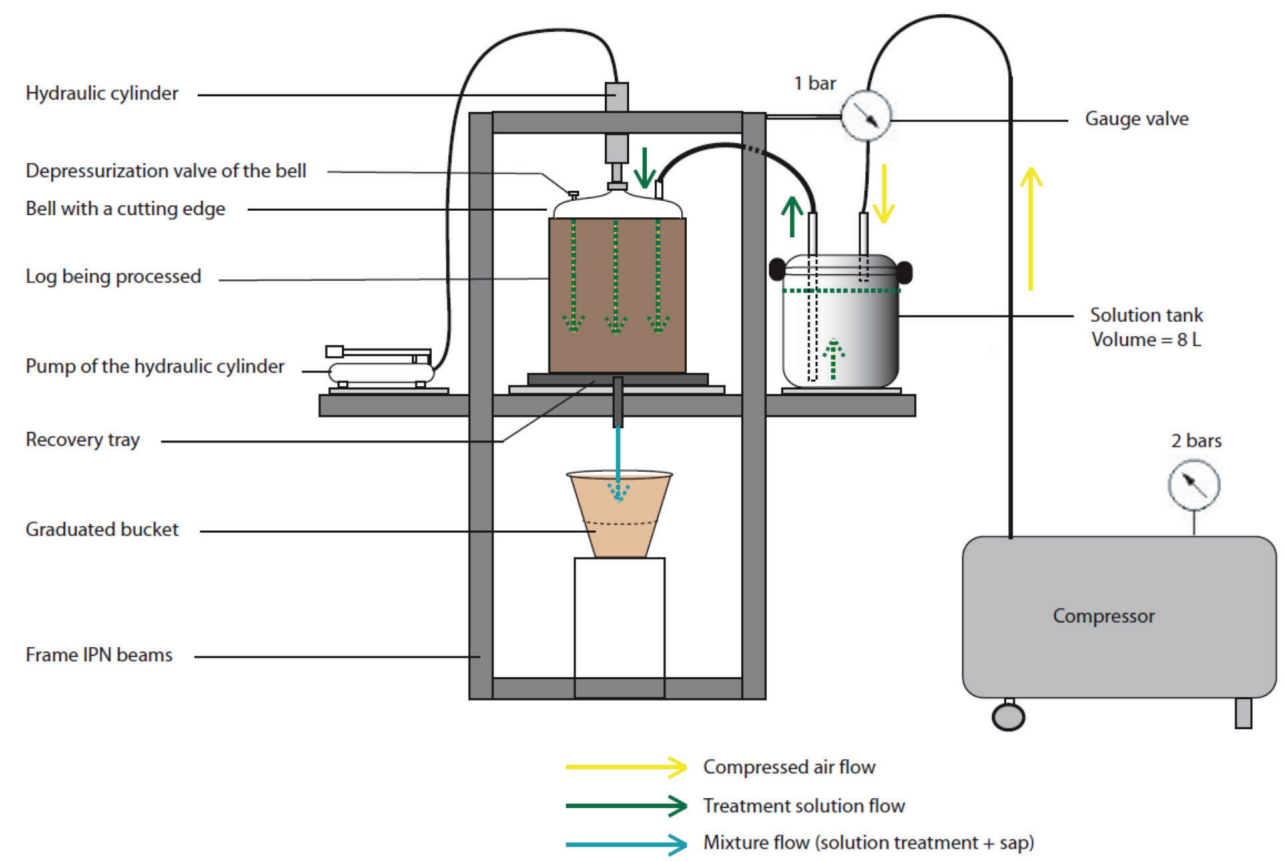

Figure 1. Scheme of the laboratory prototype used for the axial impregnation tests.

\section{Treatment}

\section{Chemical}

Logs were axially impregnated with an aqueous solution containing 5\% of Tanalith E3492, provided by Arch Timber Protection. Active ingredients contained in Tanalith E3492 are constituted of copper carbonate $(20,5 \% \mathrm{w} / \mathrm{w})$, propiconazole $(0,23 \% \mathrm{w} / \mathrm{w})$, tebuconazole $(0,23 \% \mathrm{w} / \mathrm{w})$ and boric acid $(4,5 \%$ $\mathrm{w} / \mathrm{w})$. Such chromium free preservative systems have been proposed to substitute CCA formulations and constitute a model preservative easily quantifiable through copper analysis for our study (Temiz et al. 2014, Treu et al. 2011, Islam et al. 2009).

\section{Axial Impregnation}

Axial impregnation tests have been carried out on the laboratory prototype available at the Thiérache Wood Centre.

The treatment was carried out within 24 hours in order to avoid the wood drying. Furthermore, the $\log$ to treat has to present a cross section as flat as possible: this allows obtaining a good bell / log contact and prevents leakage. Thus, a slice of a few centimeters thick, at the base end of the log (root system side) is cut just before the treatment.

For each wood species tested, the axial impregnation test requires a $\log$ of $1,2 \mathrm{~m}$ in length by $25 \mathrm{~cm}$ in diameter. This $\log$ is cut up into four logs of $25 \mathrm{~cm}$ in length after severing ends. For each trunk, a log was kept as a control.

To carry out the logs treatment; 7,6 L of water and $400 \mathrm{~g}$ of Tanalith E3492 are vigorously mixed in a bucket with a stick. This solution is then introduced into the impregnation tank. The bell with a cutting edge ( $20 \mathrm{~cm}$ in diameter) is pressed onto the cross section of the log with a hydraulic jack (15 tons), until the contact on all the circumference of the bell / log link is sealed. The tight contact is important 
to avoid spilling, and consequently, the risk of incomplete treatment. The solution may then be brought under slight pressure ( 1 bar), obtained by a compressor and a valve for regulating the pressure. The log must be positioned so that the impregnation bell is placed on the root system side (hence the importance of marking logs when felling trees). Other sealing methods could be used to connect the bell to the log; some of them have been developed at Thiérache Wood Center allowing impregnating the trunk of higher diameter (Damay 2014).

The liquid (free water and sap) contained in the log starts to flow as soon as it is pushed by the impregnation solution; at the beginning, it is clear and pure, but afterwards the diluted treatment product appears and becomes increasingly concentrated. The criteria characterizing the full impregnation of a $\log$ is the volume of rejected solution. According to the available data from the Thiérache Wood Centre, the volume of solution to impregnate is approximately equal to 0,3 times the volume of timber to be treated. The volume of impregnated solution is assumed to be identical to the volume of rejected solution, flowing at the end of the log. Thus, it is important to place a graduated bucket under the recovery tank, to measure the volume of rejected solution. As a precaution, the impregnated volume was equal to 0,4 times the volume of wood to be treated in order to ensure uniform treatment. The volume of impregnating solution is calculated using the following formula:

$$
V_{\text {sol }}=0,4 \times \pi \times R_{\text {bell }}^{2} \times L_{\log }
$$

With:

$$
\begin{array}{ll}
\text { - } & V_{\text {sol }}: \text { volume of impregnating solution }\left(\mathrm{m}^{3}\right) \\
\text { - } & R_{\text {bell }}: \text { radius of the impregnation bell (m) } \\
\text { - } & L_{l o g}: \text { length of the log to be treated }(\mathrm{m})
\end{array}
$$

According to the size of the samples (0,25 m length) and to the radius of the impregnation bell $(0,10 \mathrm{~m})$; the volume of the impregnation solution is of approximately $3,14 \mathrm{~L}$.

The treatment was carried out within 24 hours after the felling. Then the logs were stored 14 days so as to allow the diffusion of the treatment solution throughout the wood. The logs were then sawn into two parts to avoid drying splits. The logs were then sawn with a band saw and machined with a planer to produce $30 \mathrm{~mm}$ thickness boards. Again, the cut logs into stud were stored 30 days to allow the drying of the boards. 


\section{Sample collection}

After treatment, machining and drying, samples for the determination of copper were taken according to the cutting plane shown in Figure 2.

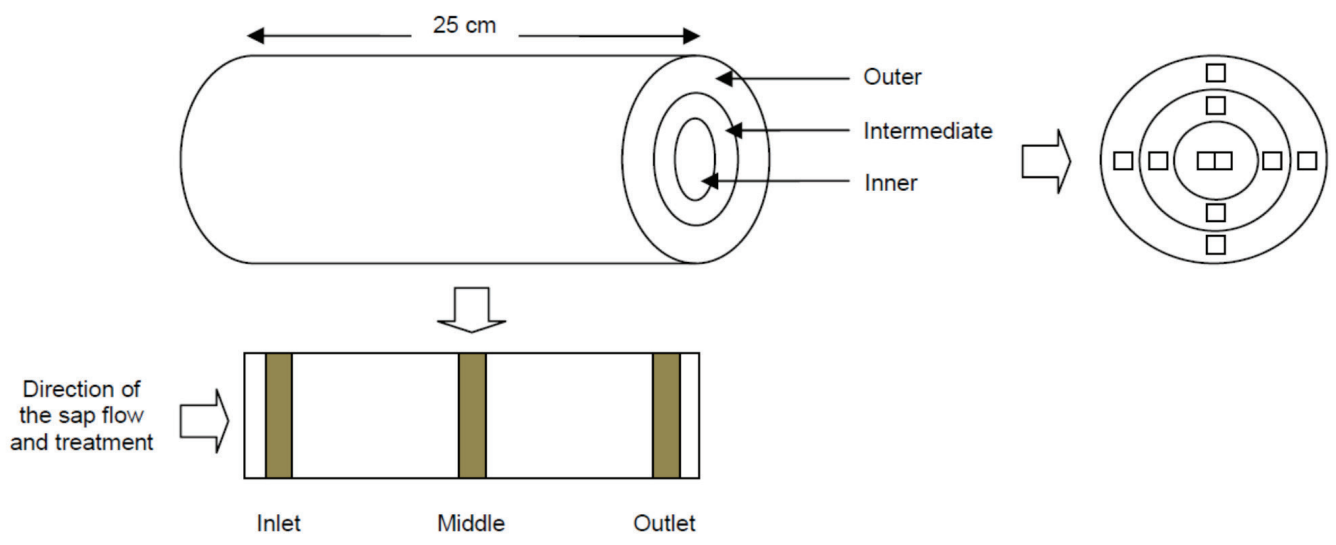

Figure 2. Cutting plane of test samples for the determination of the copper concentrations.

Three longitudinal positions are determined in relation to the direction of circulation of the treatment product in the log - inlet, middle and outlet; and for each of these cross sections, three concentric zones are defined - inner, intermediate and outer.

Thus, ten samples were taken for each cross section or 30 samples per log. These samples were then ground in a Fritsch grinder ring (Vibrating Mill Pulverisette Cup 9, 3 times 40 seconds at 1000 RPM) with the grinding set $\mathrm{N}^{\circ} 484125$, then dried at $103^{\circ} \mathrm{C}$ in a ventilated oven for further analysis.

\section{Characterization - Determination of copper concentrations}

The dried powders obtained from the treated wood samples were mineralized in order to determine the copper. The mineralization of the impregnated wood powders was done following a procedure inspired by the American standard A7-04, from the American Wood Protection Association (AWPA A7-04, 2004). Copper was analyzed by atomic absorption spectrometry.

A mass of $0,2 \mathrm{~g}$ of dried treated wood powder is precisely weighed in a $50 \mathrm{~mL}$ Erlenmeyer flask and $10 \mathrm{~mL}$ of nitric acid $\left(\mathrm{HNO}_{3}, 68 \%\right.$, Sigma Aldrich) is added. The Erlenmeyer is then placed on a fluidized bed (bed of graphite) at a temperature of $85^{\circ} \mathrm{C}$. The reaction produces irritant redhead' fumes (nitrogen dioxide, $\left.\mathrm{NO}_{2}\right)$. When there is no more redhead fumes, $4 \mathrm{~mL}$ of hydrogen peroxide $\left(\mathrm{H}_{2} \mathrm{O}_{2}, 30 \%\right.$, VWR - Prolabo) is added dropwise. If some particles remain in the solution, $2 \mathrm{~mL}$ of additional hydrogen peroxide $\left(\mathrm{H}_{2} \mathrm{O}_{2}, 30 \%\right)$ is added dropwise; this addition may be repeated as long as the solution remains turbid. Then, the solution is transferred to a $50 \mathrm{~mL}$ volumetric flask and completed up to precisely $50 \mathrm{~mL}$ by addition of distilled water. In parallel, a range of four standards is prepared from a stock solution at $1000 \mathrm{mg} \mathrm{L}^{-1}$ (Standard AAS Cu, Fluka, $1000 \mathrm{mg} \mathrm{L}^{-1} \pm 4 \mathrm{mg} \mathrm{L}^{-1}$ ). Standard concentrations were $1 \mathrm{mg} \mathrm{L}^{-1}$, $3 \mathrm{mg} \mathrm{L}^{-1}, 5 \mathrm{mg} \mathrm{L}^{-1}$ and $8 \mathrm{mg} \mathrm{L}^{-1}$. 
Then, the copper contained in the mineralized wood solutions is measured using an atomic absorption spectrometer Varian 220 FS, provided with a lamp for copper analysis. This equipment allows nebulizing the solution to be tested in a flame of acetylene at about $2500^{\circ} \mathrm{C}$; the absorbance measurement at the specific wavelength of the studied metal, in this case $324,8 \mathrm{~nm}$ for the copper, is used to determine the copper concentration of the solution (Subra et al. 1999).

\section{RESULTS AND DISCUSSION}

The choice of wood species tested by axial impregnation meets specific criteria: it is addressed to low durability species, impregnable species, and should use local woods available in quantity. The four hardwood species tested - ash (Fraxinus excelsior), beech (Fagus sylvatica), birch (Betula pubescens), and hornbeam (Carpinus betulus) - are the most common hardwood species - with oak, which is considered naturally durable - in the forests of north east of France (Delécluse and Junot 2007). According to Rayzal (Rayzal 2002), these four species present low natural durability, and among them, beech, birch, and hornbeam are deemed impregnable. Conversely, ash is considered as a refractory species. This allows a comparison of the effectiveness of the axial impregnation method depending on the species' impregnability.

Tanalith E3492 was used to validate the axial impregnation method. It has fungicidal and insecticidal properties. It was chosen for two main reasons. First, the major active material in its composition is the copper carbonate; the copper element is easy to dose after wood mineralization, as shown in the literature (Rapp et al. 1997); furthermore, the copper ions are dissolved in aqueous solution, so they easily spread into the wood, which provides a good impregnation. Tanalith E3492 was chosen as test product because of its certification by FCBA in the CTBp+ list of preventive preservation products, in view of further development at the Thiérache Wood Centre in order to obtain the label CTB-Bois + . The concentration of Tanalith E3492, the volume of impregnated solution, the duration of treatment and the treatment pressure were chosen based on previous axial impregnation studies performed in the framework of European programs VALUE, WOOD Plus INNOVATION, INTERREG III and IV. After treatment, the logs were stored to allow the diffusion of the product throughout the whole of the wood fibers. Then these logs were cut according to a precise plan to achieve a "mapping" of the copper concentrations in the wood. Product migration through the log, and the distribution of the product in the log were studied according to longitudinal and radial directions.

After grinding and mineralization of the sample, copper was analyzed by atomic absorption spectrometry (AAS) in order to determine its concentration in the log according to the longitudinal and radial directions. The atomic absorption spectrometer directly provides the concentrations of copper, depending on the calibration, after converting the measurement of the absorbance at $324,8 \mathrm{~nm}$. These copper analyses allow observing the impregnability of tested species for a treatment by axial impregnation with Tanalith E3492. For each log and each cross sectional, the data is the average of two samples for the inner zone close to the axis of the log, and four samples for the two outer zones. Results are presented in Table 1. 
Table 1. Copper concentrations in wood log depending on radial and longitudinal positions for the four tested species.

\begin{tabular}{|c|c|c|c|c|}
\hline \multirow{3}{*}{ Species } & \multirow{3}{*}{ Longitudinal position } & \multicolumn{3}{|c|}{ Radial position } \\
\hline & & Inner & Intermediate & Outer \\
\hline & & \multicolumn{3}{|c|}{$\mathrm{mg} / \mathrm{g}$ of dry wood } \\
\hline \multirow{3}{*}{ Birch } & Inlet & $1,38 \pm 0,11$ & $1,41 \pm 0,12$ & $1,12 \pm 0,15$ \\
\hline & Middle & $1,36 \pm 0,06$ & $1,33 \pm 0,12$ & $1,11 \pm 0,14$ \\
\hline & Outlet & $1,40 \pm 0,09$ & $1,25 \pm 0,07$ & $1,12 \pm 0,14$ \\
\hline \multirow{3}{*}{ Hornbeam } & Inlet & $1,09 \pm 0,13$ & $1,25 \pm 0,17$ & $1,08 \pm 0,12$ \\
\hline & Middle & $0,85 \pm 0,12$ & $1,19 \pm 0,07$ & $1,05 \pm 0,10$ \\
\hline & Outlet & $0,75 \pm 0,03$ & $0,99 \pm 0,06$ & $0,92 \pm 0,08$ \\
\hline \multirow{3}{*}{ Beech } & Inlet & $2,14 \pm 0,19$ & $2,06 \pm 0,11$ & $2,32 \pm 0,28$ \\
\hline & Middle & $1,90 \pm 0,09$ & $1,76 \pm 0,11$ & $2,29 \pm 0,42$ \\
\hline & Outlet & $1,94 \pm 0,06$ & $1,83 \pm 0,23$ & $2,46 \pm 0,44$ \\
\hline \multirow{3}{*}{ Ash } & Inlet & $0,19 \pm 0,00$ & $0,15 \pm 0,03$ & $0,32 \pm 0,06$ \\
\hline & Middle & $0,01 \pm 0,00$ & $0,00 \pm 0,00$ & $0,09 \pm 0,03$ \\
\hline & Outlet & $0,00 \pm 0,00$ & $0,00 \pm 0,00$ & $0,08 \pm 0,02$ \\
\hline
\end{tabular}

As regards to the determination of copper in the treated birch by axial impregnation, the distribution is relatively uniform, on both the cross-sectional and the longitudinal sections. Mean concentration for the 30 samples was $1,3 \pm 0,06 \mathrm{mg}$ of copper per gram of dry wood. Concentrations appear to be slightly lower in the peripheral area of the log.

The distribution of copper in the hornbeam log is fairly uniform both in cross-sectional and in longitudinal section. Nevertheless, it can be seen that the concentrations of copper in the inner zone of the log are slightly lower, particularly in middle and outlet cross-sections. The average concentration was 1,0 $\pm 0,08 \mathrm{mg}$ of copper per gram of dry wood. There is also a gradient lengthwise in the log. This gradient could be even more distinct if longer log had been treated. However, the treatment homogeneity could probably be improved by increasing the volume of treatment solution allowing a more homogeneous concentration of the product within the longitudinal direction and a more homogeneous diffusion in the wood cell walls (Perre and Karimi 2002).

As compared to birch, beech log was visually well treated. Mapping of copper concentrations in the $\log$ shows its regular distribution, both in cross-sections and in longitudinal section. Beech is the wood species which keeps the most copper. The average copper content is about 2,1 $\pm 0,12 \mathrm{mg}$ per gram of dry wood. 
Assuming that copper is homogenously distributed in wood, it is possible to adapt the final concentration in the wood according to the initial concentration of the impregnation solution.

In contrast to the other species, the ash log shows a heterogeneous poor copper concentration profile. Low concentrations of copper are detected in the input cross-section, of the order of $0,2 \mathrm{mg}$ of copper per gram of dry wood; however, copper is not detected in middle and output cross-sections, except for a very low concentration of $0,1 \mathrm{mg}$ of copper per gram of dry wood in the outer area of the log. The ash wood vessels seem refractory to impregnation, at least in the heartwood. Sapwood is slightly permeable, as shown in the mapping of copper concentrations. Furthermore, it is important to note that the axial impregnation of the ash log required significantly longer than for logs of the other species: in fact, after 45 minutes of treatment at 1 bar pressure, 2 liters of solution only had been rejected, mainly of the sap, while only 3 to 5 minutes of treatment at 1 bar pressure had been needed to bring out more than 4 liters of liquid (sap and free water) mixed with a small amount of impregnation solution, for the other species. The ash is considered in the literature as a moderately permeable species by the conventional impregnation method of vacuum / pressure (Benoit 2008), corroborating our results. The axial impregnation does not allow the achievement of a homogeneous impregnation of the ash log.

Knowing the average copper concentration in sawdusts and wood density, it is possible to estimate the quantity of Tanalith E3492 retained within the wood allowing determination of wood use classes. These results are presented in Table 2 .

Table 2. Density, average copper concentrations in wood log, estimated Tanalith E3492 retention and corresponding use classes.

\begin{tabular}{lcccc}
\hline Species & Density & $\begin{array}{c}\text { Average Copper } \\
\text { concentration }\end{array}$ & $\begin{array}{c}\text { Tanalith E3492 } \\
\text { retention }\end{array}$ & Use classe \\
\cline { 2 - 4 } & $\mathrm{mg} / \mathrm{g}$ of dry wood & $\mathrm{kg} / \mathrm{m}^{3}$ & \\
\hline Birch & 0,62 & 1,28 & 7,53 & $3 \mathrm{~B}$ (without termites) \\
\hline Hornbeam & 0,83 & 1,02 & 8,03 & $3 \mathrm{~B}$ (without termites) \\
\hline Beech & 0,68 & 2,08 & 13,42 & 4 \\
\hline Ash & 0,72 & 0,09 & 0,61 & 1 \\
\hline
\end{tabular}

According to the CTBp+ classification, retention of Tanalith E3492 should be above the threshold of $7,1 \mathrm{~kg} / \mathrm{m}^{3}$ for applications in use class 3 without termites and above $10,3 \mathrm{~kg} / \mathrm{m}^{3}$ for applications in use class 3 with termites, while retentions of $13,3 \mathrm{~kg} / \mathrm{m}^{3}$ should be obtained for applications in use class 4 as defined in AWPA U1-14 and NF 335-2EN standards. In the case of treated hornbeam, mean Tanalith retention was estimated to $8,03 \mathrm{~kg}$ per cubic meter of wood allowing wood utilization in exterior conditions above ground without termites corresponding to use class 3. Similar results were obtained for birch wood with potential application in use class 3. The average Tanalith E3492 concentration of beech wood of $13,42 \mathrm{~kg} / \mathrm{m}^{3}$ is just over the value of $13,3 \mathrm{~kg} / \mathrm{m}^{3}$ recommended by CTBp+ indicating potential applications in class use 4. Ash presents very low Tanalith E3492 concentration incompatible with outdoor applications. In all cases, an increase of the treatment solution concentration may result in an higher Tanalith retention in wood allowing utilization of wood in higher class uses. 


\section{CONCLUSIONS}

The results obtained in this preliminary study indicate that axial impregnation is suitable for impregnation of treatable hardwood species. Indeed, three out of the four studied species were homogeneously treated with this method. Moreover, the results are consistent with the classification of the species impregnability proposed by Rayzal, in which the birch, hornbeam and beech are considered as impregnable species, while ash is described as a refractory species to impregnation. In the future, it would be interesting to test longer logs and larger diameter to validate the method on industrial scale using larger bell sizes in order to fit with the diameter of the log to be impregnated.

Beech is the species that has retained the most copper $(2,1 \pm 0,24 \mathrm{mg}$ of copper per gram of dry wood) throughout its volume. Birch and hornbeam present slightly lower copper concentrations after treatment, the average copper retained in these species are $1,3 \pm 0,13$ and 1,0 $\pm 0,16 \mathrm{mg}$ of copper per gram of dry wood, respectively. These differences are likely to be related to the water content of the $\operatorname{logs}$ at the time of the treatment, and to the volume of sap replaced during impregnation. Finally, the ash cannot be treated uniformly by the axial impregnation method.

According to our results, the axial impregnation appears as a suitable method to impregnate treatable hardwood species constituting an attractive alternative to classical vacuum pressure impregnation methods.

\section{ACKNOWLEDGEMENTS}

The authors would like to acknowledge the French National Association of Research and Technology (ANRT, contract $\mathrm{N}^{\circ}$ 1003-2009) and the European Union (INTERREG IV, Eurowood) for financial support. LERMAB is supported by a grant overseen by the French National Research Agency (ANR) as part of the "Investissements d'Avenir" program (ANR-11-LABX-0002-01. Lab of Excellence ARBRE).

\section{REFERENCES}

American Wood Protection Association Standard. AWPA. 2004. American Wood Protection Association Standard. Standard for Wet Ashing Procedures for Preparing Wood for Chemical Analysis. AWPA A7-04. Birmingham, AL, USA..

American Wood Protection Association Standard. AWPA. 2014. Use Category System: User Specification for treated wood. AWPA U1-14.

Benoit, Y.FCBA. 2008. Le Guide des Essences de bois. $2^{\text {ème }}$ édition. Paris : Eyrolles. 148 p. ISBN : 978-2-212-12086-8.

Damay, J. 2014. Développement de nouveaux traitements du bois basés sur le procédé d'imprégnation axiale. Thèse de doctorat. Nancy : 27 novembre 2014. 245 p. 
CTBp+. 2013. Liste des produits industriels de traitement preventifs. $n^{\circ}$ MQ-CERT/13-042, éditée le 07 mars 2013, 20 p.

Hakkou, M.; Petrissans, M.; Gerardin, P.; Zoulalian, A. 2006. Investigations of the reasons for fungal durability of heat-treated beech wood. Polymer Degradation and Stability 2: 393-397.

Hill, C.A.S. 2006. Wood Modification : Chemical, Thermal and Other Processes. $1^{\text {st }}$ edition. Chichester : John Wiley \& Sons. 239 p. ISBN : 978-0-470-02172-9.

Islam, M.N.; Ando, K.; Yamauchi, H.; Hattori, N. 2009. Preservative treatment of douglas-fir lumber by the passive impregnation method with copper azole. European Journal of Wood Products $67: 77-81$

NF EN 335-2. 2007. Durabilité du Bois et des Matériaux dérivés du Bois - Définition des classes d'emploi

Perre, P.; Karimi, A. 2002. Fluid migration in two speciesof beech (Fagus sylvatica and Fagus orientalis): a percolation model able to account for macroscopic measurmentss and anatomical obsercvations. Maderas. Ciencia y tecnologia 4(1): 50-68.

Rapp, A.O.; Brandt, K.; Peek, R.D.; Schmitt, U. 1997. Quantitative measurement and chemical analysis of wood dust collected in German woodworking companies. Holz als Roh- und Werkstoff 55(3): 141-147.

Rayzal, M. 2002. Préservation du bois - Guide d'emploi des normes. Paris : AFPB et CTBA. 129 p.

Rowell, R.; Ibach, R.E.; James, M.; Thomas, N. 2009. Understanding decay resistance, dimensional stability and strength changes in heat treated and acetylated wood. Wood material science and engineering $4(1): 14-22$.

Subra, I. ; Hubert, G. ; Aubert, S. ; Hery, M. ; El Cabache, J.M. 1999. Hygiène et sécurité du travail. Exposition professionnelle aux métaux lors de l'usinage des bois traités au cuivre, chrome, arsenic. Nancy : INRS. Cahiers de notes documentaires $175:$ 61-68.

Temiz, A. ; Alfredsen, G.; Yildiz, U.C.; Gezer, E.D.; Kose, G.; Akbas, S.; Yildiz, S. 2014. Leaching and decay resistance of alder and pine wood treated with copper based wood preservatives. Maderas. Ciencia y tecnologia 16(1): 63-76.

Thomasson, G.; Capizzi, J.; Dost, F.; Morrell, J.; Miller, D. 2006. Wood Preservation and Wood Products Treatment. Training Manual. Oregon State University Extension Service, August 2006. 24 p. [online]<http://www.oregon.gov/ODA/shared/Documents/Publications/PesticidesPARC/ WoodProductsTreatmentTrainingManual.pdf $>$

Treu, A.; Larnoy, E.; Militz, H. 2011. Process related copper leaching during a combined wood preservation process. European Journal of Wood Products 69: 263-269. 